Dietary Intake of n-6 Fatty Acids Modulates Effect of Apolipoprotein A5 Gene on Plasma Fasting Triglycerides, Remnant Lipoprotein Concentrations, and Lipoprotein Particle Size: The Framingham Heart Study

Chao-Qiang Lai, Dolores Corella, Serkalem Demissie, L. Adrienne Cupples, Xian Adiconis, Yueping Zhu, Laurence D. Parnell, Katherine L. Tucker and Jose M. Ordovas

Circulation 2006;113;2062-2070; originally published online Apr 24, 2006; DOI: 10.1161/CIRCULATIONAHA.105.577296

Circulation is published by the American Heart Association. 7272 Greenville Avenue, Dallas, TX 72514

Copyright @ 2006 American Heart Association. All rights reserved. Print ISSN: 0009-7322. Online ISSN: $1524-4539$

The online version of this article, along with updated information and services, is located on the World Wide Web at: http://circ.ahajournals.org/cgi/content/full/113/17/2062

Subscriptions: Information about subscribing to Circulation is online at http://circ.ahajournals.org/subscriptions/

Permissions: Permissions \& Rights Desk, Lippincott Williams \& Wilkins, a division of Wolters Kluwer Health, 351 West Camden Street, Baltimore, MD 21202-2436. Phone: 410-528-4050. Fax: 410-528-8550. E-mail:

journalpermissions@1ww.com

Reprints: Information about reprints can be found online at http://www.lww.com/reprints 


\title{
Dietary Intake of n-6 Fatty Acids Modulates Effect of Apolipoprotein A5 Gene on Plasma Fasting Triglycerides, Remnant Lipoprotein Concentrations, and Lipoprotein Particle Size
}

\author{
The Framingham Heart Study
}

\author{
Chao-Qiang Lai, PhD; Dolores Corella, PhD; Serkalem Demissie, PhD; L. Adrienne Cupples, PhD; \\ Xian Adiconis, MSc; Yueping Zhu, MSc; Laurence D. Parnell, PhD; \\ Katherine L. Tucker, PhD; Jose M. Ordovas, PhD
}

Background-Apolipoprotein A5 gene (APOA5) variation is associated with plasma triglycerides (TGs). However, little is known about whether dietary fat modulates this association.

Methods and Results-We investigated the interaction between APOA5 gene variation and dietary fat in determining plasma fasting TGs, remnant-like particle (RLP) concentrations, and lipoprotein particle size in 1001 men and 1147 women who were Framingham Heart Study participants. Polymorphisms $-1131 \mathrm{~T}>\mathrm{C}$ and $56 \mathrm{C}>\mathrm{G}$, representing 2 independent haplotypes, were analyzed. Significant gene-diet interactions between the $-1131 \mathrm{~T}>\mathrm{C}$ polymorphism and polyunsaturated fatty acid (PUFA) intake were found $(P<0.001)$ in determining fasting TGs, RLP concentrations, and particle size, but these interactions were not found for the $56 \mathrm{C}>\mathrm{G}$ polymorphism. The $-1131 \mathrm{C}$ allele was associated with higher fasting TGs and RLP concentrations $(P<0.01)$ in only the subjects consuming a high-PUFA diet $(>6 \%$ of total energy). No heterogeneity by sex was found. These interactions showed a dose-response effect when PUFA intake was considered as a continuous variable $(P<0.01)$. Similar interactions were found for the sizes of VLDL and LDL particles. Only in carriers of the $-1131 \mathrm{C}$ allele did the size of these particles increase (VLDL) or decrease (LDL) as PUFA intake increased $(P<0.01)$. We further analyzed the effects of $n-6$ and $n-3$ fatty acids and found that the PUFA-APOA5 interactions were specific for dietary n-6 fatty acids.

Conclusions - Higher n-6 (but not n-3) PUFA intake increased fasting TGs, RLP concentrations, and VLDL size and decreased LDL size in APOA5 - 1131C carriers, suggesting that n-6 PUFA-rich diets are related to a more atherogenic lipid profile in these subjects. (Circulation. 2006;113:2062-2070.)

Key Words: diet $\boldsymbol{\square}$ fatty acids $\boldsymbol{\square}$ genetics $\boldsymbol{\|}$ lipids $\boldsymbol{\square}$ lipoproteins

$\mathrm{T}$ he impact of hypertriglyceridemia on coronary heart disease risk has long been a matter of debate; however, evidence supporting the prognostic value of this lipid fraction has been gained during the past decade. ${ }^{1,2}$ Triglyceride (TG)-rich lipoproteins comprise a great variety of nascent and metabolically modified lipoprotein particles, and they are especially relevant during the postprandial state. ${ }^{3}$ Remnant lipoproteins have also been shown to promote atherogenesis, ${ }^{4-6}$ and plasma remnantlike particles (RLPs) can be measured by an antibody-based assay. ${ }^{7}$ In the Framingham Offspring Study, ${ }^{8}$ RLPs were significantly increased in women with diabetes and in men compared with control subjects without diabetes.

\section{Clinical Perspective p 2070}

Apolipoprotein A5 (APOA5) ${ }^{9,10}$ is found preferentially on HDL but is thought to transfer to VLDL during the postprandial state. ${ }^{11}$ Despite its very low levels in plasma, APOA5 is an important regulator of TG-rich lipoprotein (TRL) metabolism. ${ }^{12}$ Two mechanisms have been proposed. The first suggests a role of APOA5 in VLDL assembly ${ }^{13,14}$; the second supports the possibility that APOA5 may be an activator of intravascular TG hydrolysis by lipoprotein lipase (LPL). ${ }^{15-17}$ However, both proposals are not mutually exclusive, and these mechanisms may be

Received July 20, 2005; revision received February 17, 2006; accepted February 23, 2006.

From the Nutrition and Genomics Laboratory (C-Q.L., D.C., X.A., Y.Z., L.D.P., J.M.O.) and the Dietary Assessment and Epidemiology Research Program (K.L.T.), JM-USDA Human Nutrition Research Center on Aging, Tufts University, Boston, Mass; the Genetic and Molecular Epidemiology Unit (D.C.), School of Medicine, University of Valencia, Valencia, Spain; and the School of Public Health (S.D., L.A.C.), Boston University, Boston, Mass. Guest Editor for this article was Robert H. Eckel, MD.

Correspondence to Dr C.-Q. Lai, Nutrition and Genomics Laboratory, JM-USDA-HNRCA, Tufts University, 711 Washington St, Boston, MA 02111. E-mail chao.lai@tufts.edu

(C) 2006 American Heart Association, Inc.

Circulation is available at http://www.circulationaha.org 
working simultaneously or alternatively, depending on specific metabolic situations.

Several common APOA5 single-nucleotide polymorphisms (SNPs) have been associated with increased plasma total TG, RLP, and VLDL concentrations. ${ }^{18-22}$ Moreover, current knowledge suggests an association between APOA5 and postprandial lipemia that could be modulated by the type of dietary fat. ${ }^{23,24}$ In this regard, polyunsaturated fatty acids (PUFAs) are known modulators of gene expression. ${ }^{25}$ Along these lines, we have reported that dietary PUFAs interact with the leucine to valine (L162V) substitution at the peroxisome proliferator-activated receptor- $\alpha$ (PPAR- $\alpha)$ gene in determining plasma TG and apolipoprotein C3 concentrations in the Framingham Study participants. ${ }^{26}$ Considering that PPAR $-\alpha$ is a nuclear transcription factor regulating multiple genes involved in lipid metabolism (including $A P O A 5^{27}$ ), our previous results prompted us to examine the hypothesis that PUFA intake may modulate the effect of APOA5 variants on lipid metabolism. Moreover, given the different cardiovascular protection attributed to n-6 and n-3 PUFAs, ${ }^{28}$ we examined their potential interactions with APOA5 variants in a large population-based study, the Framingham Heart Study.

\section{Methods}

\section{Study Design and Subjects}

The study sample consisted of 2148 subjects who participated in the Framingham Offspring Study. ${ }^{29}$ Lipids, other cardiovascular disease (CVD) risk factors, and dietary intake were recorded for subjects who participated in the fifth examination, conducted between 1992 and $1995(\mathrm{n}=3515)$. DNA was obtained from 1987 to 1991 . The Institutional Review Board for Human Research at Boston University and Tufts University/New England Medical Center approved the protocol of the present study. All participants provided written informed consent.

The present study included only subjects with phenotypic data and complete dietary information for whom APOA5 gene variants were examined. Subjects taking lipid-lowering medications as well as subjects with any missing data on control variables (age, body mass index [BMI], smoking, alcohol consumption, diabetes status, $\beta$-blocker use, and estrogen use in women) were excluded from our analyses. Thus, data for 1001 men and 1147 women who met the above criteria were analyzed. Because nearly all subjects were white, no control for ethnicity was needed. Although in the Framingham Study recruitment of families was planned, ${ }^{29}$ in this specific cycle most participants were unrelated, and the number of individuals within each family included in the present study was very low. Thus, the 1147 women considered in the present study were distributed in 893 pedigrees, and $752(65 \%)$ were singletons. In the nonsingletons, 113 women were unrelated, and the others were mostly siblings and cousins. The 1001 men in the present study were distributed in 814 pedigrees, and 697 of the $1001(\approx 70 \%)$ were singletons. In the families, 53 men were unrelated, and the others were mostly siblings and cousins.

\section{Genetic Analysis}

Genomic DNA was isolated from peripheral blood leukocytes by standard methods. APOA5 SNPs $-1131 \mathrm{~T}>\mathrm{C}(\mathrm{rs} 662799)$, $-3 \mathrm{~A}>\mathrm{G}(\mathrm{rs} 651821), \quad \mathrm{IVS} 3+476 \mathrm{G}>\mathrm{A}(\mathrm{rs} 2072560), \quad$ and $1259 \mathrm{~T}>\mathrm{C}(\mathrm{rs} 2266788)$ and $56 \mathrm{C}>\mathrm{G}(\mathrm{rs} 3135506)$ were genotyped as previously described ${ }^{21,22}$ by use of the ABI Prism SNapShot multiplex system (Applied Biosystems, Foster City, Calif).

\section{Measurement of Plasma Lipid, Lipoprotein, and Apolipoprotein}

The standardized procedures for sample collection and biochemical analysis for TGs, total cholesterol, LDL cholesterol, and HDL cholesterol have been described previously. ${ }^{30}$ VLDL and LDL subclass distributions were determined by proton nuclear magnetic resonance spectroscopy. ${ }^{31}$ Measurements of RLP-TG and RLP cholesterol (RLP-C) concentrations have previously been described. ${ }^{7}$

\section{Dietary Assessment}

Dietary intake was estimated with the semiquantitative Willett food-frequency questionnaire (Rimm et $\mathrm{al}^{32}$ ), which specified serving sizes. This questionnaire has been validated for total PUFA intake as well as n-3 and n-6 fatty acids (FAs). ${ }^{32,33}$ Intakes of total fat, saturated fatty acids (SFAs), monounsaturated fatty acids (MUFAs), total PUFAs, and n-3 and n-6 PUFAs were expressed as percentages of total energy and were included in analyses as both continuous and categorical variables. To construct categorical variables, intakes were classified into 2 groups according to the mean value of the population (ie, groups had intakes below and above the mean). In addition, we considered together as n-3 PUFA the dietary intake of $\alpha$-linolenic acid, eicosapentaenoic acid, docosahexaenoic acid, and docosapentaenoic acid. Linoleic acid and arachidonic acid were considered together as n-6 PUFA. Tertiles of PUFA intakes (n-6 and n-3) were also considered.

\section{Statistical Analyses}

We examined all continuous variables for normality of distribution. TG, RLP-TG, and RLP total cholesterol (RLP-C) concentrations were log-transformed. Results were presented as the antilog of the estimated log values. The relationship between APOA5 genotypes, dietary PUFAs, and plasma lipid-related measures was evaluated by analysis of covariance techniques. Because the present study involved some correlated data that were due to familial relationships (siblings and cousins), we controlled for familial relationships. We used 2 approaches to accomplish these analyses. First, a generalized linear mixed-model approach, which assumed an exchangeable correlation structure among all members of a family (PROC MIXED in SAS, Cary, NC), was used. Second, because this approach could not accurately represent the true correlation structure within these pedigrees, we used a measured-genotype approach as implemented in SOLAR, a variance component-analysis computer package for quantitative traits measured in pedigrees of arbitrary size. ${ }^{34}$ In these analyses, we used several different models to adjust for potential confounders. After having checked that the results obtained using the generalized mixed model were similar to those of the SOLAR approach because of the large number of unrelated subjects in this sample, we decided to use the generalized mixed model for the adjustment of familial relationships. The interactions between dietary PUFAs (as a continuous or as a categorical variable) and the APOA5 polymorphisms were tested in a hierarchical multivariateinteraction model after controlling for potential confounders, including sex, age, BMI, smoking, alcohol consumption, total energy, fat and carbohydrate intakes, diabetes status, $\beta$-blocker use, menopausal status, and estrogen use (in women). These analyses were performed for the whole sample and for men and women separately in order to verify the homogeneity and the magnitude of the effect. Standard regression diagnostic procedures, including multicollinearity tests, homogeneity of variance tests, normal plots of the residuals, and residuals by Student $t$ test, were used to ensure the appropriateness of these models. The population means for PUFA intake and for other types of fat were considered the cutoff points to dichotomize these variables. When PUFA intake was considered as a continuous variable, its interaction with the APOA5 polymorphism was depicted by computing the predicted values for each individual from the adjusted regression model and plotting these values against PUFA intake depending on the APOA5 genotype. The haplotype analysis was carried out as previously described. ${ }^{22}$ The pairwise linkage disequilibria (LDs) between SNPs at the APOA5 locus were estimated as correlation coefficient R, with the HelixTree program using unrelated subjects. Inference and possible haplotypes were computed via an expectation-maximization algorithm. ${ }^{22}$ All reported statistical tests were 2 sided. To minimize type I errors, which are increased because of the high number of comparisons, only values of $P \leq 0.01$ were considered statistically significant. 
TABLE 1. Demographic, Biochemical, Dietary, and Genotypic Data

\begin{tabular}{|c|c|c|}
\hline $\begin{array}{l}\text { Characteristics of Participants } \\
\text { According to Sex }\end{array}$ & $\begin{array}{c}\text { Men } \\
(\mathrm{n}=1001)\end{array}$ & $\begin{array}{l}\text { Women } \\
(n=1147)\end{array}$ \\
\hline Age, y & $50.8 \pm 9.9$ & $50.1 \pm 9.6$ \\
\hline BMI, $\mathrm{kg} / \mathrm{m}^{2}$ & $27.6 \pm 3.8$ & $25.9 \pm 5.5$ \\
\hline LDL-C, mg/dL & $135 \pm 33$ & $127 \pm 35$ \\
\hline $\mathrm{HDL}-\mathrm{C}, \mathrm{mg} / \mathrm{dL}$ & $44 \pm 11$ & $56 \pm 15^{\star}$ \\
\hline $\mathrm{TG}, \mathrm{mg} / \mathrm{dL}$ & $135 \pm 97$ & $105 \pm 101^{*}$ \\
\hline RLP-TG, $\uparrow \mathrm{mg} / \mathrm{dL}$ & $30.7 \pm 45.0$ & $22.2 \pm 70.2^{*}$ \\
\hline $\mathrm{RLP}-\mathrm{C}, \dagger \mathrm{mg} / \mathrm{dL}$ & $8.54 \pm 6.79$ & $7.13 \pm 6.31^{*}$ \\
\hline LDL diameter, $\mathrm{nm}$ & $20.69 \pm 0.59$ & $21.08 \pm 0.46$ \\
\hline VLDL diameter, nm & $48.28 \pm 9.24$ & $44.20 \pm 8.58^{*}$ \\
\hline Glucose, mg/dL & $97.0 \pm 23.0$ & $91.1 \pm 19.3^{*}$ \\
\hline Energy intake, kcal/d & $2004 \pm 643$ & $1745 \pm 576^{\star}$ \\
\hline Total fat, $\mathrm{g} / \mathrm{d}$ & $67.1 \pm 27.6$ & $56.9 \pm 23.8^{*}$ \\
\hline SFA, $\%$ of energy & $10.6 \pm 2.9$ & $10.3 \pm 2.9^{*}$ \\
\hline MUFA, \% of energy & $11.5 \pm 2.6$ & $11.0 \pm 2.6^{\star}$ \\
\hline $\mathrm{n}-6$ PUFA, $\%$ of energy & $5.1 \pm 1.5$ & $5.2 \pm 1.6$ \\
\hline $\mathrm{n}-3$ PUFA, $\%$ of energy & $0.65 \pm 0.2$ & $0.71 \pm 0.2^{*}$ \\
\hline PUFA, $\%$ of energy & $5.8 \pm 1.6$ & $6.0 \pm 1.7$ \\
\hline Animal fat, $\%$ of energy & $15.9 \pm 5.5$ & $15.1 \pm 5.1^{*}$ \\
\hline Vegetable fat, $\%$ of energy & $14.0 \pm 4.4$ & $14.1 \pm 4.5$ \\
\hline Carbohydrate, $\%$ of energy & $50.2 \pm 8.5$ & $51.9 \pm 8.4$ \\
\hline Fiber, g/d & $19.1 \pm 8.2$ & $19.2 \pm 8.4$ \\
\hline Alcohol, g/d & $14.7 \pm 19.4$ & $7.2 \pm 11.8^{*}$ \\
\hline Drinkers, n (\%) & $751(75)$ & $768(67)^{\star}$ \\
\hline Smokers, n (\%) & $233(23.3)$ & $247(21.6)$ \\
\hline$\beta$-Blocker treatment, $\mathrm{n}(\%)$ & $111(11.1)$ & $73(6.3)^{\star}$ \\
\hline Diabetes status, n (\%) & $74(7.4)$ & $44(3.8)$ \\
\hline On estrogen treatment, $\mathrm{n}(\%)$ & $0(0)$ & $90(7.9)$ \\
\hline \multicolumn{3}{|l|}{$A P O A 5-1131 \mathrm{~T}>\mathrm{C}$, $\ddagger \mathrm{n}(\%)$} \\
\hline$\pi$ & $816(86.2)$ & $936(87.0)$ \\
\hline C carriers & $131(13.8)$ & $140(13.0)$ \\
\hline \multicolumn{3}{|l|}{ APOA5 56C > G, $\ddagger \mathrm{n}(\%)$} \\
\hline $\mathrm{CC}$ & $860(87.5)$ & $1002(89.1)$ \\
\hline G carriers & $123(12.5)$ & $123(11.0)$ \\
\hline
\end{tabular}

Values are mean \pm SD or $\mathrm{n}(\%)$.

*Significantly different from men $(P<0.01)$.

†Data for these variables were available for only a random sample of these participants $(n=1600)$.

ҒAP0A5 genetic data was successfully obtained in 947 men and 1076 women for the $-1131 \mathrm{~T}>\mathrm{C}$ polymorphism and for 983 men and 1125 women for the $56 \mathrm{C}>\mathrm{G}$ polymorphism.

The authors had full access to the data and take full responsibility for its integrity. All authors have read and agreed to the manuscript as written.

\section{Results}

Information about demographic, biochemical, dietary intake, and genotypic data are provided in Table 1. Five APOA5 SNPs $(-1131 \mathrm{~T}>\mathrm{C}, \quad-3 \mathrm{~A}>\mathrm{G}, \quad 56 \mathrm{C}>\mathrm{G}$, IVS3 $+476 \mathrm{G}>\mathrm{A}$, and $1259 \mathrm{~T}>\mathrm{C}$ ) were analyzed. Genotype frequencies did not deviate from Hardy-Weinberg equilibrium expectations. Allele frequencies for the rare alleles listed above were $0.069,0.071,0.059,0.064$, and 0.072 , respectively. As previously shown, ${ }^{22} 4$ of the APOA5 SNPs $(-1131 \mathrm{~T}>\mathrm{C},-3 \mathrm{~A}>\mathrm{G}, \mathrm{IVS} 3+476 \mathrm{G}>\mathrm{A}$, and $1259 \mathrm{~T}>\mathrm{C})$ were in strong LD with each other and shared the same haplotype. Pairwise $\mathrm{LD}$ coefficient $\mathrm{R}$ values between the $-1131 \mathrm{~T}>\mathrm{C}$ SNP and SNPs $-3 \mathrm{~A}>\mathrm{G}, \mathrm{IVS} 3+476 \mathrm{G}>\mathrm{A}$, and $1259 \mathrm{~T}>\mathrm{C}$ in unrelated subjects were 1,1 , and 1 , respectively $(P<0.001)$. The haplotype defined by these SNPs was named haplotype APOA $5 * 2 .{ }^{18}$ In contrast, SNP $56 \mathrm{C}>\mathrm{G}$ was independent of the aforementioned SNPs, representing a different haplotype (ie, APOA5*3). ${ }^{18}$ Pairwise LD coefficient $\mathrm{R}$ between the $-1131 \mathrm{~T}>\mathrm{C}$ SNP and $56 \mathrm{C}>\mathrm{G}$ was 0.063 . Furthermore, we investigated genediet interactions determining plasma TGs, TRL concentrations, and lipoprotein particle sizes for each of the 5 SNPs as well as for the most prevalent haplotypes (11111 [representing $86.3 \%$ of all haplotypes] and 22122 and 11211 [accounting for $6.2 \%$ and $5.7 \%$, respectively]). As expected, the analyses of each of the 4 SNPs in strong LD revealed the same interactions with the dietary PUFA intake on the variables examined, whereas no significant interactions with fat intake were observed for SNP 56C $>\mathrm{G}$ (data not shown). Accordingly, in the haplotype association analysis, we obtained statistically significant interactions $(P<0.01)$ between PUFA intake and the 22122 haplotype in determining TRL in men and women. No significant interactions were obtained when the 11211 haplotype was analyzed. Because the haplotype analysis did not show better results than did the SNP analysis with the $-1131 \mathrm{~T}>\mathrm{C}$ polymorphism, we considered this SNP to be a tag SNP of the APOA5*2 haplotype.

First, to examine the interaction between $-1131 \mathrm{~T}>\mathrm{C}$ SNP and PUFA intake, we dichotomized dietary PUFA according to the population mean $(5.92 \pm 1.7 \%, \approx 6 \%)$. Homozygotes (CC) and heterozygotes (TC) of the rare allele were combined to increase statistical power. Separate models were fitted for men and women, and although the magnitude of the effect was slightly greater in men, similar directions of effects were observed. Moreover, the homogeneity by sex was also confirmed by examining the probability value of the corresponding interaction term with sex ( $P>0.05$ for each parameter examined). Therefore, men and women were analyzed together. After multivariate control for potential confounders, a statistically significant interaction $(P<0.001)$ between SNP $-1131 \mathrm{~T}>\mathrm{C}$ and PUFA intake $(>6 \%$ or $<6 \%$ of energy) on TG concentration was found (Figure 1A). In the adjusted model, the $-1131 \mathrm{C}$ allele was associated with an increase in fasting TG $(21 \%, P=0.002)$ only in subjects consuming $>6 \%$ of energy from PUFA. However, mean fasting TG concentrations were not statistically higher in carriers of the $-1131 \mathrm{C}$ allele compared with the TT homozygotes when the PUFA consumption was low $(P=0.600)$. We observed similar and significant interactions between PUFA consumption and SNP $-1131 \mathrm{~T}>\mathrm{C}$ on RLP-TG $(P<0.001)$ and RLP-C $(P<0.001)$. As observed for fasting TGs, concentrations of RLP-TG in 

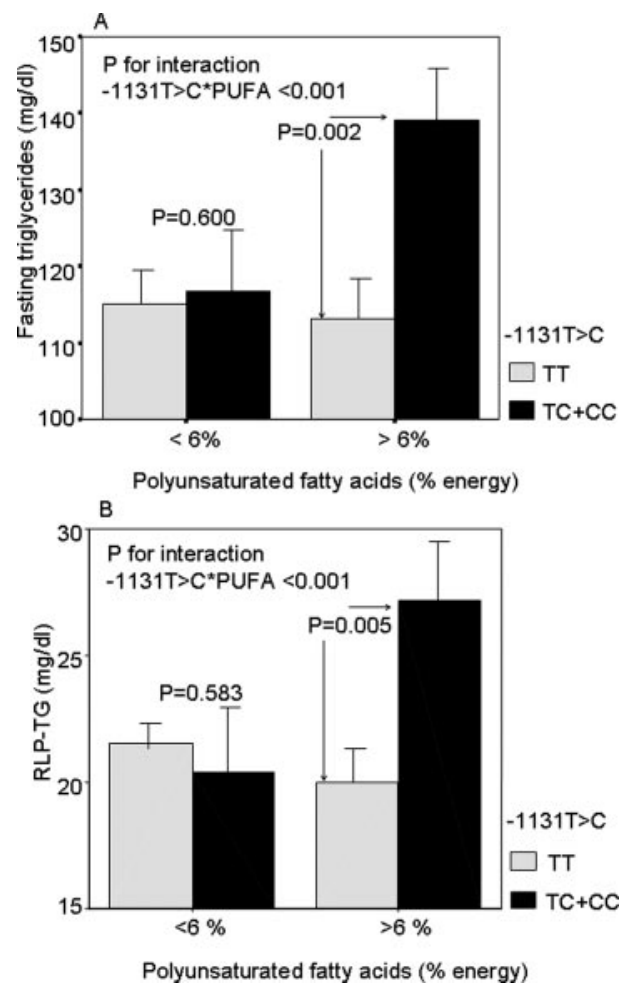

Figure 1. Mean TG $(A)$ and RLP-TG $(B)$ concentrations in men and women combined by $A P O A 5-1131 \mathrm{~T}>\mathrm{C}$ genotypes (gray bar indicates TT; black bar, TC $+\mathrm{CC}$ ) and PUFA intake categories (PUFA $<6 \%$ and PUFA $>6 \%$ ). Means were adjusted for sex, age, familial relationships, BMI, smoking, alcohol, diabetes status, menopausal status, estrogens, $\beta$-blocker use, total fat intake, carbohydrates, and energy. Mean values are antilog of the log value. Bars indicate standard error (SE) of means. SEs were computed to maintain the proportion estimated with the log transformation.

subjects carrying the $-1131 \mathrm{C}$ allele (Figure 1B) were increased $(\approx 34 \%, P=0.005)$ when they consumed more than $6 \%$ of energy from PUFAs. When we analyzed the interaction of SNP $-1131 \mathrm{~T}>\mathrm{C}$ and PUFA intake in determining LDL and VLDL sizes, we found statistically significant interactions $(P=0.01$ and $P=0.008$, respectively). These were consistent with a more atherogenic lipid profile in subjects carrying the $-1131 \mathrm{C}$ allele and consuming more than $6 \%$ of energy from PUFAs. Thus, in carriers of the $-1131 \mathrm{C}$ allele, a high PUFA intake was associated with smaller LDL particle size $(20.60 \pm 0.05 \mathrm{~nm}$ versus $20.80 \pm 0.03 \mathrm{~nm}$ in TT subjects) and also with larger VLDL size $(47.6 \pm 0.9 \mathrm{~nm}$ versus $46.5 \pm 0.5 \mathrm{~nm}$ in TT subjects). Using the same statistical models in which fat intake was dichotomized according to its corresponding population mean, we did not uncover any significant interactions between the APOA5 $-1131 \mathrm{~T}>\mathrm{C} \mathrm{SNP}$ and intake of total fat, SFAs, or MUFAs on concentrations of TGs, RLP-TGs, or RLP-C or on LDL and VLDL particle size.

To investigate whether the interaction between PUFA and APOA5 - 1131T $>\mathrm{C}$ was dose dependent, we analyzed, as continuous variables, PUFA intake as well as the intake of other fats to test the specificity of the effect. To show the homogeneity by sex, separate models for men and women (Table 2) were fitted with interactions between fat intake (total fat, SFA, MUFA, and PUFA) and the APOA5 polymorphism in determining TGs, RLP-TGs, and RLP-C concentrations and LDL and VLDL particle size by sex after controlling for potential confounders. Consistent with results for the categorical variables, we found significant interactions between PUFA intake and $-1131 \mathrm{~T}>\mathrm{C}$ SNP on TGs, RLP-TGs, RLP-C, and VLDL size in men $(P=0.003, P<0.001, P=0.003$, and $P=0.002$, respectively) and in women $(P=0.001, P<0.001, P=0.005$, and $P=0.004$, respectively). Although the interaction for LDL particle size was statistically significant only in men $(P=0.004)$, the direction of the effect was similar in women, and no significant heterogeneity by sex was found $(P=0.211)$. In the combined analysis, all these interaction terms with PUFA intake were significant. An example of the modification of the effect of the SNP $-1131 \mathrm{~T}>\mathrm{C}$ by PUFA intake on RLP-TG concentrations in men and women combined can be seen in Figure 2. Differences in slopes of the regression lines indicate that the effect of $-1131 \mathrm{~T}>\mathrm{C}$ on RLP-TG depends on the amount of PUFA consumed. High PUFA intake was associated with lower RLP-TG concentrations in TT individuals, whereas high PUFA intake was associated with elevated RLP-TG concentrations in carriers of the $\mathrm{C}$ allele. To determine whether the interaction effect on RLPs was dependent on fasting TGs, we adjusted the regression models in Table 2 for fasting TGs. After this adjustment, the statistical significance of the interaction term between the $-1131 \mathrm{~T}>\mathrm{C}$ polymorphism and PUFA intake in determining RLP decreased. For example, in the case of plasma RLP-TGs, the probability value for the interaction term for men and women (analyzed together) changed from $P<0.001$ (with no adjustment for fasting TGs) to $P=0.035$ (after adjustment for fasting TGs), revealing some degree of independence. However, considering the high correlation between fasting TGs and RLP-TGs $(r=0.8, P<0.001$ in the present study), we cannot conclude a clear independence of the effects. Finally, n-6 and n-3 FA intakes were taken as 2 categorical variables, according to the population mean $(5.10 \%$ of energy for $\mathrm{n}-6$ and $0.69 \%$ of energy for $n-3)$. Because no heterogeneity of the effects by sex was detected, data for men and women were analyzed together. After adjustment for covariates (sex, age, familial relationships, BMI, smoking, alcohol use, total fat intake, carbohydrates, energy intake, diabetes status, menopausal status, $\beta$-blocker use, and use of estrogens), statistically significant interaction effects $(P=0.007)$ were found for $\mathrm{n}-6$ FA intake and the $-1131 \mathrm{~T}>\mathrm{C}$ polymorphism in determining fasting TGs $(113 \pm 3$ and $114 \pm 3 \mathrm{mg} / \mathrm{dL}$ in TT subjects versus $120 \pm 7$ and $141 \pm 7 \mathrm{mg} / \mathrm{dL}$ in carriers of the $\mathrm{C}$ allele when consuming less or more than $5.1 \%$ of energy from n-6) and RLP-TGs (Figure 3A). No statistically significant interactions were observed between the $-1131 \mathrm{~T}>\mathrm{C}$ and $\mathrm{n}-3$ PUFA on fasting TGs $(P=0.668)$ or RLP-TGs (Figure 3B). Results for RLP-TC and VLDL and LDL particle size depending on the type of PUFA were similar. Thus, statistically significant interactions were 
TABLE 2. Interaction Between Fat Consumption (as Continuous) and the -1131T>C Polymorphisms on TG-Rich Particle Concentrations and the Size of LDL and VLDL: Multiple Regression Analysis by the Type of Fat Consumed

\begin{tabular}{|c|c|c|c|c|c|c|c|c|c|c|c|c|c|c|c|c|}
\hline & \multicolumn{4}{|c|}{ Total Fat } & \multicolumn{4}{|c|}{ SFA } & \multicolumn{4}{|c|}{ MUFA } & \multicolumn{4}{|c|}{ PUFA } \\
\hline & \multicolumn{2}{|c|}{ Men } & \multicolumn{2}{|c|}{ Women } & \multicolumn{2}{|c|}{ Men } & \multicolumn{2}{|c|}{ Women } & \multicolumn{2}{|c|}{ Men } & \multicolumn{2}{|c|}{ Women } & \multicolumn{2}{|c|}{ Men } & \multicolumn{2}{|c|}{ Women } \\
\hline & B & $P$ & B & $P$ & B & $P$ & B & $P$ & B & $P$ & B & $P$ & B & $P$ & B & $P$ \\
\hline \multicolumn{17}{|l|}{$\overline{\mathrm{TG},{ }^{*} \mathrm{mg} / \mathrm{dL}}$} \\
\hline CT+CC genotype & 1.280 & 0.533 & -1.502 & 0.217 & 1.742 & 0.078 & 1.098 & 0.627 & 1.227 & 0.573 & -1.149 & 0.631 & -1.532 & 0.031 & -1.497 & 0.018 \\
\hline Fat intake & -1.003 & 0.955 & 1.002 & 0.639 & -1.006 & 0.662 & -1.003 & 0.827 & 1.033 & 0.161 & -1.139 & 0.755 & -1.002 & 0.863 & -1.008 & 0.435 \\
\hline Interaction term & -1.003 & 0.530 & 1.019 & 0.091 & -1.038 & 0.176 & 1.006 & 0.754 & -1.005 & 0.872 & 1.027 & 0.308 & 1.105 & 0.003 & 1.096 & 0.001 \\
\hline \multicolumn{17}{|l|}{$\mathrm{RLP}-\mathrm{TG},{ }^{*} \mathrm{mg} / \mathrm{dL}$} \\
\hline CT+CC genotype & -1.257 & 0.376 & -1.855 & 0.209 & 2.148 & 0.055 & 1.076 & 0.789 & -1.426 & 0.472 & -1.166 & 0.707 & -2.944 & 0.009 & -2.038 & 0.002 \\
\hline Fat intake & -1.004 & 0.260 & 1.003 & 0.593 & 1.029 & 0.155 & -1.017 & 0.369 & -1.009 & 0.801 & -1.013 & 0.663 & -1.035 & 0.914 & -1.002 & 0.902 \\
\hline Interaction term & 1.011 & 0.942 & 1.028 & 0.105 & -1.067 & 0.116 & 0.012 & 0.622 & 1.036 & 0.419 & 1.032 & 0.389 & 1.226 & $<0.001$ & 1.161 & $<0.001$ \\
\hline \multicolumn{17}{|l|}{$\mathrm{RLP}-\mathrm{C},{ }^{*} \mathrm{mg} / \mathrm{dL}$} \\
\hline CT + CC genotype & 1.014 & 0.575 & -1.267 & 0.403 & 1.757 & 0.016 & 1.121 & 0.446 & -1.115 & 0.681 & 1.001 & 0.998 & -2.291 & 0.003 & -1.439 & 0.016 \\
\hline Fat intake & -1.002 & 0.584 & 1.002 & 0.303 & 1.013 & 0.267 & -1.014 & 0.129 & 1.011 & 0.549 & -1.013 & 0.414 & -1.023 & 0.029 & -1.006 & 0.437 \\
\hline Interaction term & 1.018 & 0.866 & 1.012 & 0.245 & -1.047 & 0.022 & -1.002 & 0.754 & 1.015 & 0.529 & 1.009 & 0.665 & 1.172 & 0.003 & 1.075 & 0.005 \\
\hline \multicolumn{17}{|l|}{ LDL particle size, nm } \\
\hline CT + CC genotype & 0.453 & 0.110 & 0.151 & 0.604 & 0.112 & 0.670 & -0.079 & 0.653 & 0.409 & 0.193 & 0.034 & 0.886 & 0.519 & 0.012 & 0.116 & 0.396 \\
\hline Fat intake & 0.004 & 0.352 & -0.003 & 0.425 & 0.011 & 0.448 & 0.018 & 0.129 & 0.001 & 0.976 & 0.038 & 0.055 & 0.001 & 0.919 & 0.022 & 0.057 \\
\hline Interaction term & -0.017 & 0.069 & -0.008 & 0.433 & -0.024 & 0.299 & 0.001 & 0.974 & -0.047 & 0.071 & -0.001 & 0.641 & -0.111 & 0.002 & -0.032 & 0.135 \\
\hline \multicolumn{17}{|l|}{ VLDL particle size, nm } \\
\hline CT + CC genotype & -10.880 & 0.843 & -11.360 & 0.049 & 5.672 & 0.166 & -2.117 & 0.499 & -4.869 & 0.317 & -9.277 & 0.036 & -8.404 & 0.031 & -8.907 & 0.008 \\
\hline Fat intake & 0.048 & 0.512 & -0.074 & 0.282 & 0.473 & 0.053 & 0.107 & 0.669 & -0.041 & 0.929 & -0.581 & 0.101 & -0.443 & 0.071 & -0.215 & 0.297 \\
\hline Interaction term & 0.100 & 0.575 & 0.404 & 0.042 & -0.538 & 0.136 & 0.253 & 0.404 & 0.412 & 0.328 & 0.885 & 0.029 & 1.409 & 0.004 & 1.553 & 0.004 \\
\hline
\end{tabular}

Adjusted $P$ values and regression coefficients (B, in milligrams per deciliter or nanometers, depending on the trait) for the main effect (genotype and fat) and interaction terms in men and women. Multivariate regression models for each type of fat and lipid trait were fitted. Models were adjusted for age, body mass index, familial relationships, smoking, alcohol, diabetes, estrogens, menopause, $\beta$-blockers, energy intake, carbohydrates, and total fat intake. The TT genotype was considered the reference category for the APOA5 -1131T $>C$ polymorphism.

Slopes for the TT and C carriers for each type of fat can be easily obtained: The corresponding fat intake term is the $T$ slope; the TC+CC genotype term $\times$ the corresponding interaction term + the $T$ slope is the slope for carriers of the $\mathrm{C}$ allele for each lipid variable.

${ }^{*}$ For log-transformed variables, antilog values were calculated.

found for n-6 intake $(P=0.004, P=0.006$, and $P=0.01$, respectively), and nonsignificant interactions $(P>0.05)$ for any parameter were detected in the case of n-3 PUFA. To illustrate the possible dose-response relationship in this interaction, $\mathrm{n}-6$ and $\mathrm{n}-3$ intake were considered as population tertiles $(<4.37 \%, 4.37 \%$ to $5.54 \%$, and $>5.54 \%$ of energy for $\mathrm{n}-6$ and $<0.58 \%, 0.58 \%$ to $0.74 \%$, and $>0.74 \%$ of energy for $\mathrm{n}-3)$. We observed significant interactions $(P<0.01)$ between $-1131 \mathrm{~T}>\mathrm{C}$ and $\mathrm{n}-6$ PUFA intake on the above variables with a clear dosage effect, whereas no significant interactions $(P>0.05)$ between the $-1131 \mathrm{~T}>\mathrm{C}$ polymorphism and n-3 PUFA were found. We present data obtained for fasting TGs and RLP-TGs as examples. Thus, a significant increase in TGs $(+26 \%)$ and RLP-TGs $(+38 \%)$ was observed when $n-6$ PUFA intake increased from the first to the third tertile in carriers of the $-1131 \mathrm{C}$ allele $(116 \pm 9,124 \pm 9$, and $146 \pm 8 \mathrm{mg} / \mathrm{dL}$, respectively, for TGs and 17.6 $\pm 2.9,18.5 \pm 3.4$, and $24.3 \pm 3.5 \mathrm{mg} / \mathrm{dL}$, respectively, for RLP-TGs). However, no increase $(0.1 \%$, $P=0.952)$ in TGs or even a nonsignificant decrease $(-12 \%, P=0.092)$ in RLP-TGs was observed in TT homozygotes as n-6 PUFA increased. With regard to n-3 PUFA, no increase in TGs or in RLP-TGs in carriers of the $-1131 \mathrm{C}$ allele was found. Moreover, in these subjects, a decrease in RLP-TG was observed as PUFA intake increased. This decrease in RLP-TG concentrations did not reach statistical significance $(P>0.05)$, but it was statistically significant in TT homozygotes $(-23 \%, P=0.005)$. These results obtained with $n-6$ and $n-3$ PUFAs suggest that the effect observed for total PUFAs may be specific to the consumption of n-6 PUFAs.

\section{Discussion}

We found a significant and consistent interaction between the APOA5 - 1131T $>$ C polymorphism (representing haplotype APOA5*2) $)^{18}$ and PUFA intake on the concentration of plasma TGs, RLP-TGs, and RLP-C as well as on VLDL and LDL sizes in the Framingham Heart Study. This gene-diet interaction was found in related and in unrelated subjects and was not confounded by ethnicity. When PUFA consumption was $>6 \%$ (population mean) of total energy intake, carriers of the $-1131 \mathrm{C}$ allele exhibited significantly higher concentrations of fasting TGs and remnant lipoproteins (RLP-TGs and RLP-C). Moreover, compared with TT individuals, carriers of the $-1131 \mathrm{C}$ allele displayed larger VLDL and smaller LDL molecules, which have been reported to increase CVD risk. ${ }^{35}$ This gene-diet interaction showed a clear dose-dependent effect as well as a biologically plausible 


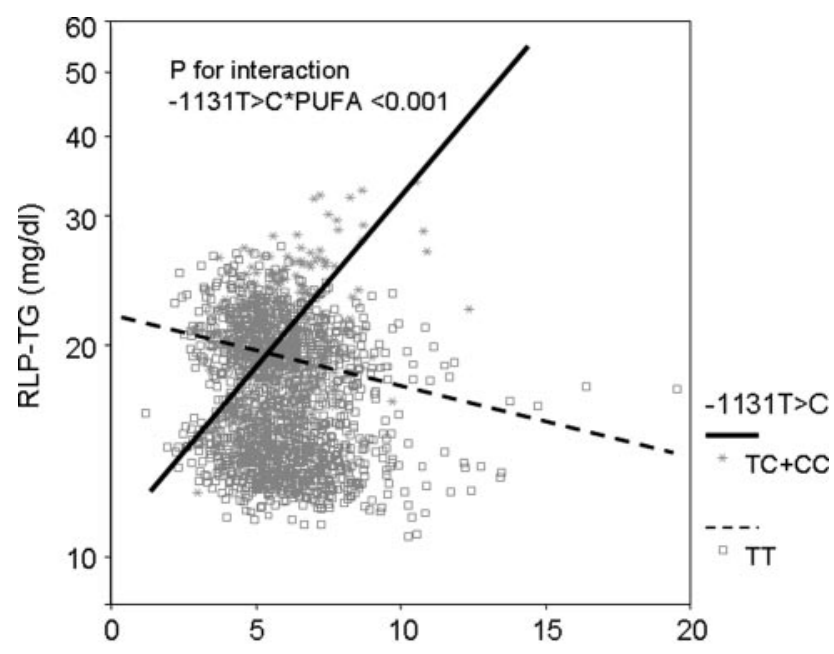

Polyunsaturated fatty acids (\% energy)

Figure 2. Scatterplot of the observed values (open squares indicate $\Pi$ allele carriers; asterisks, $\mathrm{C}$ allele carriers) and regression lines of predicted values (broken lines indicate $T T$ allele carriers; solid lines, $\mathrm{C}$ allele carriers) of RLP TG concentration by APOA5 $-1131 \mathrm{~T}>\mathrm{C}$ genotypes (in men and women combined, $\mathrm{n}=1527$ ) depending on the PUFA consumed (as a continuous variable). Predicted values were calculated from the regression models containing PUFA intake, $-1131 \mathrm{~T}>\mathrm{C}$ polymorphism, their interaction term, and the potential confounders (sex, age, familial relationships, BMI, smoking, alcohol, diabetes status, menopausal status, total fat intake, carbohydrates, estrogens, $\beta$-blocker use, and energy). $R^{2}$ of the model $=0.14 ; P<0.001$.

association consistent with the expected metabolic pathways involved. ${ }^{12,15,16}$ Two additional findings add interest to this observation. First, the interaction observed for SNP $-1131 \mathrm{~T}>\mathrm{C}$ was not shared by SNP $56 \mathrm{C}>\mathrm{G}$, which represents the other common APOA5*3 (56C $>$ G) haplotype, ${ }^{18}$ despite the fact that we reported similar associations between these 2 haplotypes and plasma TRL concentrations. ${ }^{22}$ The contrasting results suggest that the hypertriglyceridemic phenotype associated with these 2 haplotypes is driven by different mechanisms. Thus, the causative mutation for the APOA $5 * 2$ haplotype appears to be associated with dietary fat, whereas that of the APOA5*3 haplotype may not be modulated by fat intake. Second, the reported interactions are exclusively due to consumption of PUFA, with no interactions detected for total fat, SFA, or MUFA, adding evidence to the prominent role of PUFAs as modulators of genetic effects in lipid metabolism. ${ }^{25}$ Although it has been proposed that postprandial TRLs could be independent CVD risk factors and although the hypothesis is physiologically sound, ${ }^{36}$ we found significant gene-PUFA intake interaction for both fasting TG and RLP concentrations. Given the fact that fasting TGs are highly correlated with RLP-TGs, we cannot conclude in the present study a clear independence of the effects on both variables. This is consistent with recent findings that have failed to support such independence at the population level. ${ }^{37,38}$ Therefore, it will be important from a scientific point of view to clarify the role of remnants in atherogenesis by using appropriate experimental designs; however, from a clinical point of view, the measurement of
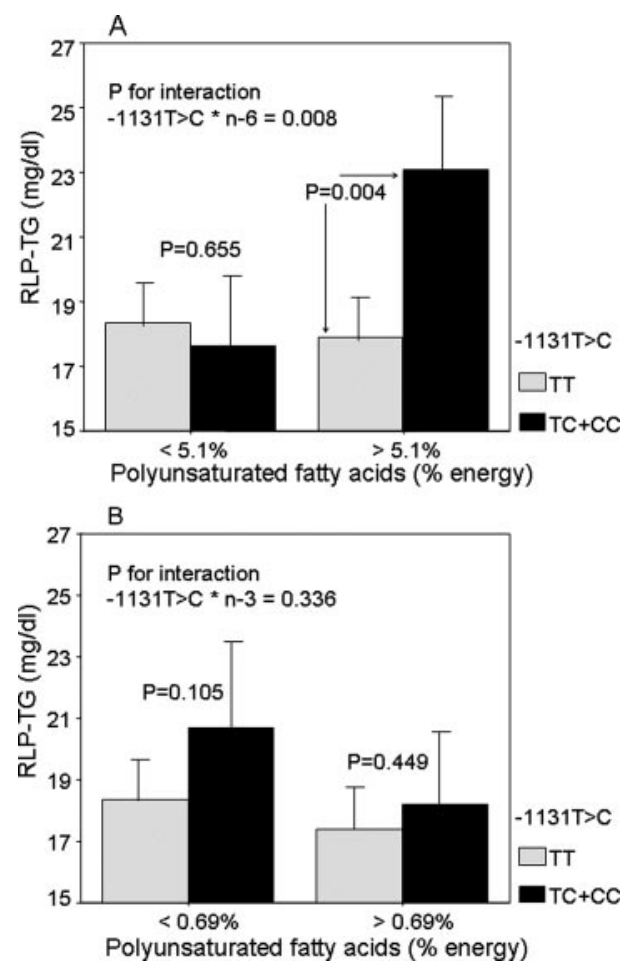

Figure 3. Mean RLP TG concentration in men and women combined depending on n-6 PUFA (A) and n-3 PUFA (B) categories (below and above the population mean) and APOA5 -1131T $>C$ genotypes (TT or $-1131 \mathrm{C}$ carriers). Means were adjusted for sex, age, familial relationships, BMI, smoking, alcohol, diabetes status, menopausal status, estrogens, $\beta$-blocker use, total fat intake, carbohydrates, and energy. Mean values are antilog of the log value. Bars indicate standard error (SE) of means. SEs were computed to maintain the proportion estimated with the log transformation.

total TGs appears to be a reasonable and practical surrogate to identify disturbances in TRL metabolism and gene-diet interactions.

Because n-3 and n-6 FAs differ in their potential preventive effect on $\mathrm{CVD},{ }^{39}$ we further investigated whether the PUFA interaction applied to the consumption of both families of PUFAs. Our results support the notion that the above-reported interactions are specific to $n-6$ PUFA. The potentially negative effects associated with elevated lipoprotein remnant concentrations observed in carriers of the APOA5 - 1131C allele who consume high n-6 PUFA were not observed for the consumption of $n-3$ PUFA. In fact, dietary n-3 FAs decreased RLP and related variables regardless of genotype. Similar findings have been reported for the arachidonate 5-lipoxygenase gene. Promoter variants at this locus are associated with increased atherosclerosis, and this association is promoted by dietary n-6 PUFA and inhibited by marine n-3 PUFAs. ${ }^{40}$

The relevance of these findings for CVD risk detection and prevention lies in the correlation between fasting and postprandial TG metabolism and CVD risk. ${ }^{3,41}$ FruchartNajib et $\mathrm{al}^{11}$ reported that overexpression of human APOA5 diminished postprandial TG response to sunflower 
oil in mice. Therefore, the observed differences between carriers of different alleles at APOA5 -1131T $>\mathrm{C}$, although still controversial, ${ }^{42}$ may be due to their differential expression. On the basis of the correlation between fasting and postprandial TG concentrations, we anticipate that compared with TT homozygotes, the APOA5 - 1131C minor allele will result in higher postprandial lipemia. In this regard, Jang et $\mathrm{al}^{24}$ demonstrated that carriers of the $-1131 \mathrm{C}$ allele had a higher chylomicron-TG area under the curve than did homozygotes for the $-1131 \mathrm{~T}$ allele after a fat load enriched in n-6 PUFA. Conversely, the allelic differences were not significant when subjects were provided with a low fat load. ${ }^{24}$ Martin et $\mathrm{al}^{23}$ also reported that male carriers of the $-1131 \mathrm{C}$ allele had significantly higher lipemic responses to a fat tolerance test. However, the responses were not significantly different by genotype after adjustment for fasting TG concentrations. Moreover, Masana et al, ${ }^{43}$ reported that carriers of the $\mathrm{C}$ allele had similar or even lower incremental diurnal triglyceridemia than did wild-type carriers after correction for fasting TG concentrations. We speculate that the high saturated fat meal used by Dwyer et $\mathrm{al}^{40}$ prevented the manifestation of the increased postprandial load, which appears to be preferentially driven by n-6 PUFA.

There is no proven mechanistic explanation for our differential findings for n-6 and n-3 FAs. However, on the basis of the evidence that TRLs are hydrolyzed by the lipolytic action of dimeric LPL, which is bound to heparan sulfate proteoglycans on the vascular endothelium, one can speculate that APOA5 targets VLDL to proteoglycans, placing VLDL in proximity to LPL. ${ }^{14-17}$ Moreover, APOA5 may activate proteoglycan-bound LPL by stabilizing the dimerized conformation or by binding to an LPL allosteric site. An important feature of this model is that for all this to happen efficiently, LPL and APOA5 must be in contact with proteoglycans on the endothelial cell membrane. ${ }^{17}$ In other words, there is margination or sequestration away from the blood of TRL during binding to endothelial LPL. The concept of margination has been illustrated by Park et al. ${ }^{44}$ Most interesting is the fact that the amount of sequestration is dependent on the type of dietary fat. A diet rich in n-3 FAs promotes the margination of the TRLs, whereas a diet rich in n-6 FAs does not promote, and may even inhibit, the margination of TRLs. Therefore, we propose the following: (1) In subjects with the most common APOA5 genotype, there is normal APOA5-induced margination of TRLs and normal hydrolysis of these lipoproteins. (2) In subjects carrying the $-1131 \mathrm{C}$ allele, there is less APOA5 available and less margination of TRLs, with subsequently increased levels of TRL, which may be accentuated in particles enriched in n-6 FAs. ${ }^{45}$ (3) Increased presence of n-3 FA strongly enhances TRL margination by yet-unknown mechanisms but probably independent of APOA5 levels. These effects overwhelm those milder effects associated with the APOA5 variant.

These findings could be relevant within the context of future development of personalized dietary recommendations because the frequency of the $-1131 \mathrm{C}$ allele varies across ethnic groups, ranging from 0.07 in whites to 0.20 in Africans, 0.30 in Hispanics, and up to 0.40 to 0.50 in Chinese and Japanese populations..$^{9,21,22}$ It is interesting to note that most dietary intervention studies using PUFArich diets have been performed in non-Hispanic whites, ${ }^{46}$ in whom frequencies of the high-TG-associated APOA5 alleles are relatively low. Hence, the overall CVD risk associated with the $-1131 \mathrm{C}$ allele in the presence of high n-6 PUFA diets may not be apparent for the population as a whole.

In summary, the observed interaction between APOA5 and PUFA consumption on TGs, RLP concentrations, and lipoprotein particle sizes suggests that higher n-6 PUFA intake increases plasma TGs and RLPs and decreases LDL particle size in carriers of the $-1131 \mathrm{C}$ allele, contributing to a more atherogenic lipid profile for this subset of the population. Most interesting, this interaction was not observed for n-3 PUFA.

Medical societies and government bodies have embraced the concept of nutrition as a major player in the epidemic of cardiovascular disease (CVD) and potentially in its control. However, some scientists remain uncertain about what constitutes the optimal diet for atherosclerosis prevention and therapy. One of the major reasons for this uncertainty is the lack of conclusive results from dietary clinical trials. The bases for the inconsistencies are the many other factors affecting CVD risk and risk factors, including age, sex, physical activity, alcohol use, smoking, and genetic background. A more complete understanding of these factors and a thoughtful use of this information should help in the identification of vulnerable populations or persons who will benefit from more personalized and mechanistic-based dietary recommendations. This potential for better prevention and therapy can be developed within the context of nutritional genomics that may provide the tools to achieve effective dietary prevention and therapy for CVDs. In summary, some time in the future, clinicians will be able to quickly identify a patient's DNA profile for coronary artery disease risk and then get immediate information on his or her metabolic response to a particular diet. The findings of this research contribute to this future by showing that high dietary PUFA n-6 may not result in atherosclerosis protection for a subpopulation of subjects characterized by the presence of the polymorphism in the promoter region of the APOA5 gene. However, this subgroup may substantially benefit from increased PUFA n-3 consumption.

\section{Acknowledgments}

This study was supported by National Heart, Lung, and Blood Institute contract N01-HC-25195 and grant HL-54776, by contracts 53-K06-5-10 and 58-1950-9-001 from the US Department of Agriculture Research Service, and by grants from the American Heart Association (0335432T) and the Spanish Ministerio de Educación (PR2004-0054).

\section{Disclosures}

None. 


\section{References}

1. Fruchart JC, Nierman MC, Stroes ES, Kastelein JJ, Duriez P New risk factors for atherosclerosis and patient risk assessment. Circulation. 2004; 109(23 suppl III):III-15-III-19.

2. Hokanson JE, Austin MA. Plasma triglyceride level is a risk factor for cardiovascular disease independent of high-density lipoprotein cholesterol level: a meta-analysis of population-based prospective studies. J Cardiovasc Risk. 1996;3:213-219.

3. Karpe F. Postprandial lipoprotein metabolism and atherosclerosis. J Intern Med. 1999;246:341-355.

4. Hodis HN, Mack WJ, Azen SP, Alaupovic P, Pogoda JM, LaBree L, Hemphill LC, Kramsch DM, Blankenhorn DH. Triglyceride- and cholesterol-rich lipoproteins have a differential effect on mild/moderate and severe lesion progression as assessed by quantitative coronary angiography in a controlled trial of lovastatin. Circulation. 1994;90: 42-49.

5. Luc G, Fievet C, Arveiler D, Evans AE, Bard JM, Cambien F, Fruchart JC, Ducimetiere P. Apolipoproteins C-III and E in apoB and non-apoBcontaining lipoproteins in two populations at contrasting risk for myocardial infarction: the ECTIM study: Etude Cas Temoins sur Infarctus du Myocarde. J Lipid Res. 1996;37:508-517.

6. Sacks FM, Alaupovic P, Moye LA, Cole TG, Sussex B, Stampfer MJ, Pfeffer MA, Braunwald E. VLDL, apolipoproteins B, CIII, and E, and risk of recurrent coronary events in the Cholesterol and Recurrent Events (CARE) trial. Circulation. 2000;102:1886-1892.

7. McNamara JR, Shah PK, Nakajima K, Cupples LA, Wilson PW, Ordovas JM, Schaefer EJ. Remnant-like particle cholesterol is an independent CVD disease risk factor in women: results from the Framingham Heart Study. Atherosclerosis. 2001;154:229-236.

8. Schaefer EJ, McNamara JR, Shah PK, Nakajima K, Cupples LA, Ordovas JM, Wilson PW. Elevated remnant-like particle cholesterol and triglyceride levels in diabetic men and women in the Framingham Offspring Study. Diabetes Care. 2002;25:989-994.

9. Pennacchio LA, Olivier M, Hubacek JA, Cohen JC, Cox DR, Fruchart JC, Krauss RM, Rubin EM. An apolipoprotein influencing triglycerides in humans and mice revealed by comparative sequencing. Science. 2001; 294:169-173.

10. van der Vliet HN, Sammels MG, Leegwater AC, Levels JH, Reitsma PH, Boers W, Chamuleau RA. APOA5: a novel apolipoprotein associated with an early phase of liver regeneration. J Biol Chem. 2001;276: 44512-44520.

11. Fruchart-Najib J, Bauge E, Niculescu LS, Pham T, Thomas B, Rommens C, Majd Z, Brewer B, Pennacchio LA, Fruchart JC. Mechanism of triglyceride lowering in mice expressing human APOA5. Biochem Biophys Res Commun. 2004;319:397-404.

12. Rensen PC, van Dijk KW, Havekes LM. APOA5: low concentration, high impact. Arterioscler Thromb Vasc Biol. 2005;25:2445-2447.

13. Weinberg RB, Cook VR, Beckstead JA, Martin DD, Gallagher JW, Shelness GS, Ryan RO. Structure and interfacial properties of human APOA5. J Biol Chem. 2003;278:34438-34444.

14. Schaap FG, Rensen PC, Voshol PJ, Vrins C, van der Vliet HN, Chamuleau RA, Havekes LM, Groen AK, van Dijk KW. APOA5 reduces plasma triglycerides by inhibiting VLDL-TG production and stimulating lipoprotein lipase-mediated VLDL-TG hydrolysis. J Biol Chem. 2004; 279:27941-27947.

15. Grosskopf I, Baroukh N, Lee SJ, Kamari Y, Harats D, Rubin EM, Pennacchio LA, Cooper AD. APOA5 deficiency results in marked hypertriglyceridemia attributable to decreased lipolysis of triglyceride-rich lipoproteins and removal of their remnants. Arterioscler Thromb Vasc Biol. 2005;25:2573-2579.

16. Marcais C, Verges B, Charriere S, Pruneta V, Merlin M, Billon S, Perrot L, Drai J, Sassolas A, Pennacchio LA, Fruchart-Najib J, Fruchart JC, Durlach V, Moulin P. Apoa5 Q139X truncation predisposes to late-onset hyperchylomicronemia due to lipoprotein lipase impairment. J Clin Invest. 2005;115:2862-2869.

17. Merkel M, Loeffler B, Kluger M, Fabig N, Geppert G, Pennacchio LA, Laatsch A, Heeren J. APOA5 accelerates plasma hydrolysis of triglyceride-rich lipoproteins by interaction with proteoglycan-bound lipoprotein lipase. J Biol Chem. 2005;280:21553-21560.

18. Pennacchio LA, Olivier M, Hubacek JA, Krauss RM, Rubin EM, Cohen JC. Two independent APOA5 haplotypes influence human plasma triglyceride levels. Hum Mol Genet. 2002;11:3031-3038.

19. Talmud PJ, Hawe E, Martin S, Olivier M, Miller GJ, Rubin EM, Pennacchio LA, Humphries SE. Relative contribution of variation within the APOC3/A4/A5 gene cluster in determining plasma triglycerides. Hum Mol Genet. 2002;11:3039-3046.

20. Nabika T, Nasreen S, Kobayashi S, Masuda J. The genetic effect of the APOA5 gene on the serum triglyceride level in Japanese. Atherosclerosis. 2002;165:201-204.

21. Lai CQ, Tai ES, Tan CE, Cutter J, Chew SK, Zhu YP, Adiconis X, Ordovas JM. The APOA5 locus is a strong determinant of plasma triglyceride concentrations across ethnic groups in Singapore. J Lipid Res. 2003;44:2365-2373.

22. Lai CQ, Demissie S, Cupples LA, Zhu Y, Adiconis X, Parnell LD, Corella D, Ordovas JM. Influence of the APOA5 locus on plasma triglyceride, lipoprotein subclasses, and CVD risk in the Framingham Heart Study. J Lipid Res. 2004;45:2096-2105.

23. Martin S, Nicaud V, Humphries SE, Talmud PJ, on behalf of the EARS group. Contribution of APOA5 gene variants to plasma triglyceride determination and to the response to both fat and glucose tolerance challenges. Biochim Biophys Acta. 2003;1637:217-225.

24. Jang Y, Kim JY, Kim OY, Lee JE, Cho H, Ordovas JM, Lee JH. The $-1131 \mathrm{~T}->\mathrm{C}$ polymorphism in the APOA5 gene is associated with postprandial hypertriacylglycerolemia; elevated small, dense LDL concentrations; and oxidative stress in nonobese Korean men. Am J Clin Nutr. 2004;80:832-840.

25. Sampath H, Ntambi JM. Polyunsaturated fatty acid regulation of genes of lipid metabolism. Annu Rev Nutr. 2005;25:317-340.

26. Tai ES, Corella D, Demissie S, Cupples LA, Coltell O, Schaefer EJ, Tucker KL, Ordovas JM; Framingham Heart Study. Polyunsaturated fatty acids interact with the PPARA-L162V polymorphism to affect plasma triglyceride and apolipoprotein C3 concentrations in the Framingham Heart Study. J Nutr. 2005;135:397-403.

27. Prieur X, Coste H, Rodriguez JC. The human APOA5 gene is regulated by PPARA and contains a novel farnesoid X-activated receptor response element. J Biol Chem. 2003;278:25468-25480.

28. Siscovick DS, Lemaitre RN, Mozaffarian D. The fish story: a diet-heart hypothesis with clinical implications: n-3 polyunsaturated fatty acids, myocardial vulnerability, and sudden death. Circulation. 2003;107: 2632-2634.

29. Feinleib M, Kannel WB, Garrison RJ, McNamara PM, Castelli WP. The Framingham Offspring Study: design and preliminary data. Prev Med. $1975 ; 4: 518-525$.

30. Cupples LA, Gagnon DR, Kannel WB. Long- and short-term risk of sudden coronary death. Circulation. 1992;85(suppl I):I-11-I-18.

31. Freedman DS, Otvos JD, Jeyarajah EJ, Barboriak JJ, Anderson AJ, Walker JA. Relation of lipoprotein subclasses as measured by proton nuclear magnetic resonance spectroscopy to CAD. Arterioscler Thromb Vasc Biol. 1998;18:1046-1053.

32. Rimm EB, Giovannucci EL, Stampfer MJ, Colditz GA, Litin LB, Willett WC. Reproducibility and validity of an expanded self-administered semiquantitative food frequency questionnaire among male health professionals. Am J Epidemiol. 1992;135:1114-1126.

33. Hunter DJ, Rimm EB, Sacks FM, Stampfer MJ, Colditz GA, Litin LB, Willett WC. Comparison of measures of fatty acid intake by subcutaneous fat aspirate, food frequency questionnaire, and diet records in a free-living population of US men. Am J Epidemiol. 1992;135:418-427.

34. Almasy L, Blangero J. Multipoint quantitative-trait linkage analysis in general pedigrees. Am J Hum Genet. 1998;62:1198-1211.

35. Williams KJ, Tabas I. The response-to-retention hypothesis of atherogenesis reinforced. Curr Opin Lipidol. 1998;9:471-474.

36. Zilversmit DB. Atherogenesis: a postprandial phenomenon. Circulation. 1979;60:473-485.

37. Imke C, Rodriguez BL, Grove JS, McNamara JR, Waslien C, Katz AR, Willcox B, Yano K, Curb JD. Are remnant-like particles independent predictors of coronary heart disease incidence? the Honolulu Heart Study. Arterioscler Thromb Vasc Biol. 2005;25:1718-1722.

38. van Oostrom AJ, Real JT, Carmena R, Ascaso JF, Castro Cabezas M. Daylong triglyceridaemia in healthy Mediterranean and Northern European subjects. Neth J Med. 2004;62:279-285.

39. Simopoulos AP. Essential fatty acids in health and chronic disease. Am J Clin Nutr. 1999; 70:560S-569S.

40. Dwyer JH, Allayee H, Dwyer KM, Fan J, Wu H, Mar R, Lusis AJ, Mehrabian M. Arachidonate 5-lipoxygenase promoter genotype, dietary arachidonic acid, and atherosclerosis. N Engl J Med. 2004;350:29-37.

41. Marcoux C, Tremblay M, Fredenrich A, Jacques H, Krimbou L, Nakajima K, Davignon J, Cohn JS. Plasma remnant-like particle lipid apolipoprotein levels in normolipidemic and hyperlipidemic subjects. Atherosclerosis. 1998;139:161-171. 
42. Talmud PJ, Palmen J, Putt W, Lins L, Humphries SE. Determination of the functionality of common APOA5 polymorphisms. J Biol Chem. 2005;280:28215-28220.

43. Masana L, Ribalta J, Salazar J, Fernandez-Ballart J, Joven J, Cabezas MC. The apolipoprotein AV gene and diurnal triglyceridaemia in normolipidaemic subjects. Clin Chem Lab Med. 2003;41:517-521.

44. Park Y, Jones PG, Harris WS. Triacylglycerol-rich lipoprotein margination: a potential surrogate for whole-body lipoprotein lipase activity and effects of eicosapentaenoic and docosahexaenoic acids. Am J Clin Nutr. 2004;80:45-50.

45. Sanders TA, Oakley FR, Miller GJ, Mitropoulos KA, Crook D, Oliver MF. Influence of n- 6 versus n-3 polyunsaturated fatty acids in diets low in saturated fatty acids on plasma lipoproteins and hemostatic factors. Arterioscler Thromb Vasc Biol. 1997;17:3449-3460.

46. Wijendran V, Hayes KC. Dietary n-6 and n-3 fatty acid balance and cardiovascular health. Annu Rev Nutr. 2004;24:597-615.

\section{CLINICAL PERSPECTIVE}

Medical societies and government bodies have embraced the concept of nutrition as a major player in the epidemic of cardiovascular disease (CVD) and potentially in its control. However, some scientists remain uncertain about what constitutes the optimal diet for atherosclerosis prevention and therapy. One of the major reasons for this uncertainty is the lack of conclusive results from dietary clinical trials. The bases for the inconsistencies are the many other factors affecting CVD risk and risk factors, including age, sex, physical activity, alcohol use, smoking, and genetic background. A more complete understanding of these factors and a thoughtful use of this information should help in the identification of vulnerable populations or persons who will benefit from more personalized and mechanistic-based dietary recommendations. This potential for better prevention and therapy can be developed within the context of nutritional genomics that may provide the tools to achieve effective dietary prevention and therapy for CVDs. In summary, some time in the future, clinicians will be able to quickly identify a patient's DNA profile for coronary artery disease risk and then obtain immediate information on his or her metabolic response to a particular diet. The findings of this research contribute to this future by showing that high dietary PUFA n-6 may not result in atherosclerosis protection for a subpopulation of subjects characterized by the presence of the polymorphism in the promoter region of the APOA5 gene. However, this subgroup may substantially benefit from increased PUFA n-3 consumption. 